\title{
Asian dust outflow in the PBL and free atmosphere retrieved by NASA CALIPSO and an assimilated dust transport model
}

\author{
Y. Hara ${ }^{1}$, K. Yumimoto ${ }^{2}$, I. Uno ${ }^{2}$, A. Shimizu ${ }^{1}$, N. Sugimoto ${ }^{1}$, Z. Liu ${ }^{3}$, and D. M. Winker ${ }^{4}$ \\ ${ }^{1}$ National Institute for Environmental Studies, Tsukuba, Ibaraki, Japan \\ ${ }^{2}$ Research Institute for Applied Mechanics, Kyushu University, Fukuoka, Japan \\ ${ }^{3}$ National Institute of Aerospace, Hampton, VA 23666, USA \\ ${ }^{4}$ NASA Langley Research Center, Hampton, VA 23681, USA
}

Received: 6 March 2008 - Published in Atmos. Chem. Phys. Discuss.: 13 May 2008

Revised: 14 January 2009 - Accepted: 19 January 2009 - Published: 17 February 2009

\begin{abstract}
Three-dimensional structures of Asian dust transport in the planetary boundary layer (PBL) and free atmosphere occurring successively during the end of May 2007 were clarified using results of space-borne backscatter lidar, Cloud-Aerosol Lidar with Orthogonal Polarization (CALIOP), and results obtained using a data-assimilated version of a dust transport model (RC4) based on a groundbased NIES lidar network. The dust layer depths and the vertical and horizontal structure simulated by RC4 agreed with those of CALIOP observations from the dust source region to the far-downstream region. Two important transport mechanisms of Asian dust in the PBL and free atmosphere were clarified: a low-level dust outbreak within the dry slot region of a well-developed low-pressure system, and formation of an elevated dust layer within the warm sector of a low-pressure system. We also represent the aging of pure dust particles using the particle depolarization ratio (PDR) at $532 \mathrm{~nm}$ and the color ratio (CR) at $1064 \mathrm{~nm}$ and $532 \mathrm{~nm}$. Aerosols with high PDR were observed uniformly over the dust source region. While the dust cloud was transported to the eastern downwind regions, aerosols with low PDR and high CR occur in the layer of less than $1 \mathrm{~km}$ height, suggesting a mixing state of spherical aerosols and dust in the surface layer.
\end{abstract}

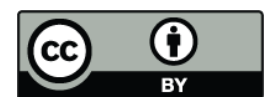

Correspondence to: Y. Hara (hara.yukari@nies.go.jp)

\section{Introduction}

Asian dust affects not only air quality in the planetary boundary layer (PBL) but also the regional/global radiative balance. Asian dust emitted from desert regions in Northern China and Mongolia is usually trapped and transported within the PBL, but it is sometimes elevated to the free atmosphere (FA), thereby providing favorable conditions to reach thousands of kilometers to North America (Takemura et al., 2002; Uno et al., 2001). Numerical modeling is an effective means to clarify the detailed 3-D structure of wide-range dust transport. Nevertheless, dust modeling engenders several uncertainties, especially in relation to dust emission processes. Therefore, detailed 3-D dust observation is important for improving dust model performance (e.g., dust concentration level over the source region, horizontal scale, and vertical thickness of the dust layer).

Ground-based lidars are powerful instruments that provide data related to important vertical structures of aerosol and cloud layers as well as aerosol optical properties. They can provide a vertical profile of spherical (pollution), nonspherical (dust) aerosol particles, and particle size information from two-wavelength lidar signals (Sugimoto et al., 2006), which is very important for understanding of dust phenomena.

Space-based top-down active measurement is another powerful system for dust distribution. Actually, a NASA space-borne backscatter lidar, Cloud-Aerosol Lidar with Orthogonal Polarization (CALIOP) onboard CALIPSO, has provided high-resolution vertical profiles of clouds and aerosols since June 2006 (Winker et al., 2007). It can detect

Published by Copernicus Publications on behalf of the European Geosciences Union. 


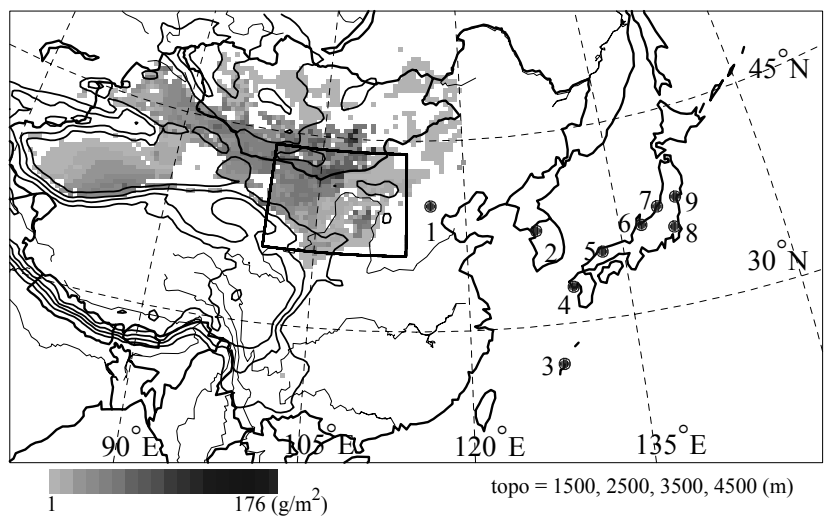

Fig. 1. Model domain and distribution of emission intensity (gray tone level). Dots represent NIES lidar network locations. Contour lines are the topographical elevations. The NIES lidar sites are: 1, Beijing; 2, Seoul; 3, Hedo; 4, Nagasaki; 5, Matsue; 6, Toyama; 7, Niigata; 8, Tsukuba; and 9, Sendai. The rectangular box encloses the Gobi region defined for Fig. 3.

dust particles quantitatively from source to downwind regions. Nevertheless, it presents some difficulties in providing aerosol information under optically thick aerosol and cloudy conditions. A more detailed understanding of dust emission and transport necessitates integration of results of the dust transport model and CALIOP observations (Uno et al., 2008).

Large-scale dust storms over Eastern Asia occurred continually during 21-31 May 2007. This paper presents a detailed integrated analysis of 3-D dust structure based on the NIES Lidar network, CALIOP observations, and results of a four-dimensional variational (4DVAR) data assimilation version of a dust transport model (Yumimoto et al., 2007, 2008). We will also show the dust transport within the PBL and the dust uplift within the warm sector of the low-pressure system and describe the importance of dust uplift in the warm sector for long-range transport of Asian dust.

\section{Dust emission/transport model and observation data}

We used the RAMS/CFORS-4DVAR dust transport model (RC4; Yumimoto et al., 2007, 2008). The RC4 is built on a meso-scale meteorological model RAMS (ver. 4.3) using its optional scalar transport options. The 4DVAR system consists of a forward CTM, its adjoint model, and an optimization process. For this study, we applied RC4 by assimilating the dust extinction coefficient derived from the NIES Lidar network. The RC4 domain is centered at $37.5^{\circ} \mathrm{N}, 115^{\circ} \mathrm{E}$ on a rotated polar stereographic system (see Fig. 1). The horizontal grids are $180 \times 100$ grids with $40 \mathrm{~km}$ resolution. The vertical layer has 40 stretched layers extending from the surface to $23 \mathrm{~km}$. ( $140 \mathrm{~m}$ at the surface to $650 \mathrm{~m}$ at the top) in terrain-following coordinates. Meteorological boundary conditions to RAMS are taken from NCEP/NCAR reanalysis data with $2.5^{\circ} \times 2.5^{\circ}$ resolution of 6 -h intervals. The simulation was performed from 1-31 May 2007 with zero initial dust concentration. The assimilation was performed during 16-31 May.

Table 1 presents NIES lidar site locations. We selected nine lidar sites (Beijing, Seoul, Hedo, Nagasaki, Matsue, Toyama, Niigata, Tsukuba, and Sendai; in Fig. 1) from the NIES lidar network (Sugimoto et al., 2006), which specify high spatial and temporal resolution. The extinction coefficient was derived based on the backward Fernald's method (Fernald, 1984) by setting a boundary condition at $6 \mathrm{~km}$ and $\mathrm{S}_{1}=50 \mathrm{sr}$ (Liu et al., 2002). The contribution of mineral dust to the total extinction coefficient is determined using the particle depolarization ratio (Shimizu et al., 2004). Total dust emission was accumulated from 16-31 May 2007 over the whole simulation domain (Table 1); a 17\% dust emission reduction was achieved using the RC4 model to give optimal agreement with the NIES lidar measurement. Details of the data assimilation of the RC4 dust model were described in Yumimoto et al. (2007, 2008).

The CALIOP measurement is used for comparison in this paper. Level 1B (ver. 1.20) CALIOP data (horizontal resolution of $333 \mathrm{~m}$ ) provide profiles of the total attenuated backscatter coefficient at $532 / 1064 \mathrm{~nm}$ and the volume depolarization ratio $(\delta)$ at $532 \mathrm{~nm}$. The CALIOP Level 2 (horizontal resolution of $5 \mathrm{~km}$ ) processing extracts features (clouds, aerosols, surface, etc.) included in a lidar profile. Version 1.20 of Level 2 products are layer-averaged attenuated optical properties along with cloud-aerosol discrimination (CAD) results (Liu et al., 2004). The CAD indicator enables discrimination between cloud (positive value) and aerosol (negative value) data. The dust extinction coefficients were derived using Fernald's inversion (Fernald, 1984) by setting the lidar ratio $\mathrm{S}_{1}=30 \mathrm{sr}$, as described by Shimizu et al. (2004). Inversion started from $z=14 \mathrm{~km}$ down to the ground surface. In this study, Level 1B data are averaged by 20 profiles and interpolated to Level 2's horizontal resolution $(5 \mathrm{~km})$. Detailed descriptions can be found on the CALIPSO mission webpage (http://www-calipso.larc.nasa.gov/) and references therein.

A smaller value of $S_{1}=30 \mathrm{sr}$ is used in the CALIOP extinction retrieval to obtain the overall semi-quantitative aerosol profile. Consequently, the extinction coefficient retrieved from the CALIOP measurement might be smaller than that from the NIES lidar network measurements by a factor of ca. $0.6(=30 / 50)$ for optically thinner cases. Fixed $S_{1}$ might engender excessive decay within the cloud layer $\left(S_{1}\right.$ is around $20)$ and thereby overestimate aerosol under that cloud. However, this is not critical because we are mainly targeting semi-quantitative analysis of dust transport (i.e., a comparison of dust vertical structure and horizontal scale) using the CALIOP measurement. 
Table 1. Locations of NIES lidar Sites, RMSD, and Dust emission statistics.

\begin{tabular}{|c|c|c|c|c|c|}
\hline Station & Longitude ${ }^{\circ} \mathrm{E}$ & Latitude ${ }^{\circ} \mathrm{N}$ & $\begin{array}{c}\text { CTM/RMSD } \\
\text { AOT }\end{array}$ & $\begin{array}{c}\text { RC4/RMSD } \\
\text { AOT }\end{array}$ & $\begin{array}{l}\text { Reduced } \\
\text { ratio }^{\text {a } \%}\end{array}$ \\
\hline Beijing & 116.46 & 39.92 & 0.487 & 0.223 & -54.6 \\
\hline Seoul & 126.90 & 37.50 & 0.329 & 0.109 & -66.9 \\
\hline Hedo/Okinawa & 128.25 & 26.87 & 0.070 & 0.076 & +8.6 \\
\hline Nagasaki & 129.86 & 32.78 & 0.166 & 0.171 & +3.0 \\
\hline Matsue & 133.01 & 35.21 & 0.252 & 0.173 & -31.3 \\
\hline Toyama & 137.10 & 36.70 & 0.217 & 0.134 & -38.2 \\
\hline Niigata & 138.94 & 37.84 & 0.189 & 0.130 & -31.2 \\
\hline Tsukuba & 140.12 & 36.05 & 0.189 & 0.111 & -41.3 \\
\hline \multirow[t]{2}{*}{ Sendai } & 140.84 & 38.25 & 0.205 & 0.134 & -34.6 \\
\hline & & & $\begin{array}{c}\text { CTM/ } \\
\text { Emission (Tg) }\end{array}$ & $\begin{array}{c}\text { RC4/ } \\
\text { Emission (Tg) }\end{array}$ & $\begin{array}{c}\text { Difference } \\
\text { Emission }(\%)\end{array}$ \\
\hline Dust Emission & - & - & 74.9 & 61.9 & -17.4 \\
\hline
\end{tabular}

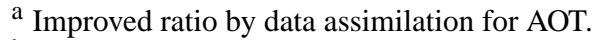

$\mathrm{b}$ Difference in dust emissions.

\section{Results and discussion}

3.1 Daily variation of meteorological conditions, dust AOT and CALIPSO observation paths

Continuous dust storms occurring in the Gobi and Sand Deserts swept across vast areas of Eastern Asia during 2131 May 2007.

Figure 2 shows the day-by-day dust transport combined with meso-scale low-pressure systems and cloud images during 21-28 May 2007. In the left column, colored and black contour lines denote the RC4 aerosol optical thickness at 09:00 UTC and the CALIPSO observation path (red lines). The path-time information of CALIPSO measurement is also shown at the bottom of the figure. Symbols of $\mathrm{L}_{1}-1-10$, $\mathrm{L}_{2}-1-5$, and the Upper Troposphere Dust layer (UTD)-1-4 $(z>6 \mathrm{~km})$ in the left column denote locations of the vertical profile analysis. The UTD was defined as the dust layer existing at altitudes higher than $6 \mathrm{~km}$. The symbol \$ shows the dust report from the WMO SYNOP surface weather. The right column includes a MODIS cloud image at OUTC and simulated $850 \mathrm{hPa}$ wind vector (pink) and potential temperature (green) with $\mathrm{L}$ and $\mathrm{H}$ symbols to show the locations of the surface low-pressure and high-pressure centers. The selected CALIPSO path does not always coincide with the center of the simulated dust area because CALIPSO observations are limited to catch the center of the dust storm in time. Moreover, the cold front with a cloud layer quite frequently accompanies the strong dust storm area, even if CALIPSO has passed over the center of the dust storm area.

Table 2 portrays the dust layer depth and layer averaged statistics (potential temperature, $\mathrm{RH} \%$, attenuated backscat- ter coefficient, and dust extinction coefficient) taken from CALIOP and the RC4 dust model for the regions of $\mathrm{L}_{1}, \mathrm{~L}_{2}$, and UTD.

The first low-pressure system $\mathrm{L}_{1}$ is located in Northern Mongolia on 21 May. In fact, $\mathrm{L}_{1}$ developed deeply as it moved eastward. On 23 May, the maximum surface wind speed is higher than $12.5 \mathrm{~m} \mathrm{~s}^{-1}$ over Southern Mongolia on 06:00 UTC, as simulated by RC4. Strong surface winds and dust mobilization occur within the dry slot area of $\mathrm{L}_{1}$ (Fig. 2c). The SYNOP observations near the region recorded the occurrence of a dust storm; the dust distribution report is consistent with that of the modeled dust AOT. The dust cloud behind the cold front moves to the east of Mongolia and Northeast China on 24 May; it then arrives in Korea on 25 May. Actually, $\mathrm{L}_{1}$ continues developing as it moves beyond the Sea of Japan, with a central sea level pressure down to $986 \mathrm{hPa}$. From late 25 to 26 May, the dust cloud came to reach a wide coverage of the Japanese archipelago. At the northern part of Mongolia, the subsequently developed low-pressure system $\mathrm{L}_{2}$ appears on 26 May. Strong winds on the southern side of the low-pressure system mobilized dust continuously; then dust clouds flowed out continuously to Southeast Korea and Southern Japan.

These two subsequent low-pressure systems were a major dynamic factor triggering the continuous outbreak of dust clouds over Eastern Asia. The region between $\mathrm{L}_{1}$ and $\mathrm{L}_{2}$ has two phase regions: cold and warm sectors. The NIES ground-based lidar network detected a heavy dust layer mainly within the planetary boundary layer (PBL), but it is also found in the elevated dust layer of the $3-5 \mathrm{~km}$ altitudes at downwind Northern Japanese sites, as depicted in Fig. 3. 

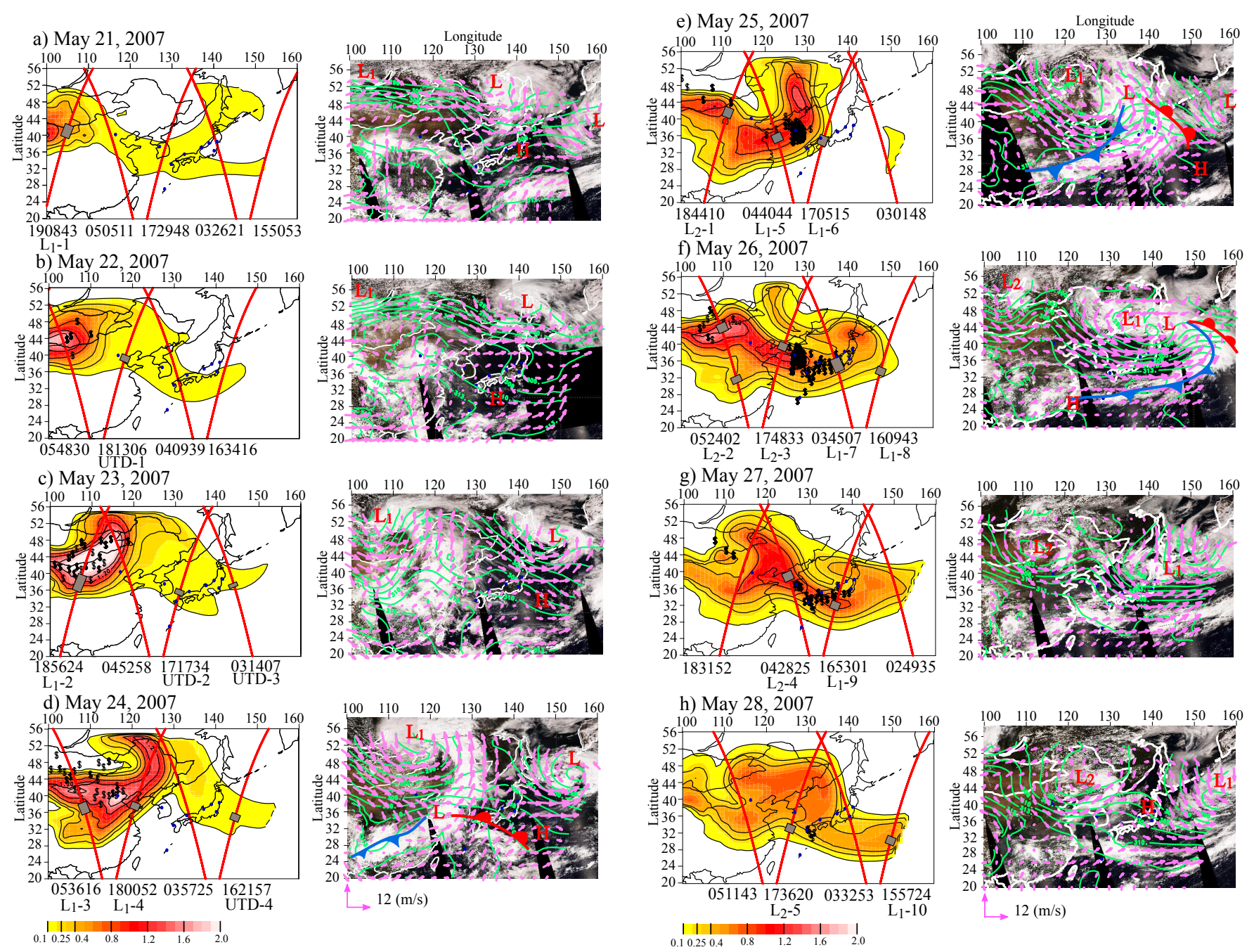

Fig. 2. (Left) CALIPSO orbit paths (red line), RC4 dust AOT (color and thick black contour) and SYNOP dust code (\$); (Right) MODIS cloud images and RC4 $850 \mathrm{hPa}$ wind field (pink) and potential temperature (green). Six-digit numbers at the bottom of each figure are the CALIPSO path times (HHMMSS).

We applied the RC4 dust model assimilated by NIES lidar observation for these events to clarify meteorological mechanisms for generating a vertical structure of dust transport. In the following sub-section, the RC4 dust model is used for detailed analysis of the 3-D dust transport structure from dust source regions to long-range downwind regions with both the NIES lidar network and NASA/CALIOP measurements.

\subsection{Time-height analysis with the NIES Lidar network}

Figure 3 shows (a) a time-series of dust AOT ( $z<6 \mathrm{~km}$ ), (b) a time-height cross section of the potential temperature and dust extinction coefficient by RC4 model for four NIES lidar sites, and (c) a time-height cross-section of observed dust extinction coefficient by NIES lidar. In Fig. 3a, the blue line represents the result without lidar data assimilation; the red line shows that with assimilation. Time series of dust AOT and time-height cross section of RC4 results in the Gobi region, including Gobi Desert, Loess Plateau, Inner Mongolia and Southern Mongolia (as defined in Fig. 1), are also presented to depict the dust storm evolution. The dust AOT from CALIOP was calculated as shown by red symbols in Fig. 3a when CALIPSO passed within $200 \mathrm{~km}$ of the NIES lidar site. The solid circle denotes CALIOP data taken under almost cloud-free conditions, whereas the open-cross circle denotes that under cloudy conditions, which might cause large error in inversion results.

The time series in the Gobi region shows that the first dust storm starts 22 May; the second dust storm occurs 26 May. The vertical structures of the dust layer observed using lidar were simulated quite well by RC4. The time delay (transport) of the first dust peak from Beijing and Seoul to Japanese sites is apparent during 24-26 May. A cold front of $\mathrm{L}_{1}$ passes 
Table 2. Characteristics of dust layers associated with low-pressure systems $\mathrm{L}_{1}$ and $\mathrm{L}_{2}$, and the downwind upper troposphere dust (UTD) layer.

\begin{tabular}{|c|c|c|c|c|c|c|c|c|c|}
\hline Label & $\begin{array}{l}\text { Date } \\
\text { May }\end{array}$ & $\begin{array}{l}\text { Path time } \\
\text { hh:mm:ss } \\
\text { UTC }\end{array}$ & $\begin{array}{l}\text { Lat. Range } \\
\left({ }^{\circ} \mathrm{N}\right)\end{array}$ & $\begin{array}{l}\text { Surface } \\
\text { Elev. } \\
(\mathrm{m})\end{array}$ & $\begin{array}{l}Z_{d} \quad \text { (Layer } \\
\text { depth)* }(\mathrm{m})\end{array}$ & $\Theta(\mathrm{K})$ & $\begin{array}{l}\mathrm{RH} \\
(\%)\end{array}$ & $\begin{array}{l}\text { Atn. Bsc. } \\
\mathrm{km}^{-1} \mathrm{sr}^{-1}\end{array}$ & $\begin{array}{l}\text { Dust Ext. } \\
\text { Coef. } * \mathrm{~km}^{-1}\end{array}$ \\
\hline $\mathrm{L}_{1-1}$ & 21 & 19:08:43 & $40-42$ & 1021 & $\begin{array}{l}3120 \\
4149\end{array}$ & 308.7 & 57.3 & 0.00240 & $\begin{array}{l}0.057 \\
0.108\end{array}$ \\
\hline $\mathrm{L}_{1-2}$ & 23 & $18: 56: 24$ & $36-39$ & 1331 & $\begin{array}{l}1320 \\
2208\end{array}$ & 300.7 & 29.8 & 0.00815 & $\begin{array}{l}0.349 \\
0.255\end{array}$ \\
\hline $\mathrm{L}_{1-3}$ & 24 & $05: 36: 16$ & $35-37$ & 915 & $\begin{array}{l}2040 \\
2458\end{array}$ & 308.0 & 14.8 & 0.00422 & $\begin{array}{l}0.150 \\
0.163\end{array}$ \\
\hline $\mathrm{L}_{1-4}$ & 24 & 18:00:52 & $36-37$ & 0 & $\begin{array}{l}2640 \\
2193\end{array}$ & 300.4 & 26.0 & 0.00387 & $\begin{array}{l}0.181 \\
0.377\end{array}$ \\
\hline $\mathrm{L}_{1-5}$ & 25 & 04:40:44 & $33-35$ & 0 & $\begin{array}{l}2040 \\
1847\end{array}$ & 301.0 & 20.1 & 0.00403 & $\begin{array}{l}0.137 \\
0.295\end{array}$ \\
\hline $\mathrm{L}_{1-6}$ & 25 & $17: 05: 15$ & $34-36$ & 0 & $\begin{array}{l}2400 \\
1994\end{array}$ & 296.9 & 48.6 & 0.00330 & $\begin{array}{l}0.086 \\
0.165\end{array}$ \\
\hline $\mathrm{L}_{1-7}$ & 25 & $18: 44: 10$ & $33-37$ & 0 & $\begin{array}{l}2400 \\
1994\end{array}$ & 298.7 & 49.9 & 0.00451 & $\begin{array}{l}0.130 \\
0.162\end{array}$ \\
\hline $\mathrm{L}_{1-8}$ & 26 & $16: 09: 43$ & $34-35$ & 0 & $\begin{array}{l}2040 \\
1847\end{array}$ & 299.2 & 38.5 & 0.00213 & $\begin{array}{l}0.082 \\
0.109\end{array}$ \\
\hline $\mathrm{L}_{1-9}$ & 27 & $16: 53: 01$ & $31-33$ & 0 & $\begin{array}{l}2520 \\
3961\end{array}$ & 303.4 & 35.0 & 0.00279 & $\begin{array}{l}0.079 \\
0.091\end{array}$ \\
\hline $\mathrm{L}_{1-10}$ & 28 & $15: 57: 24$ & $30-32$ & 0 & $\begin{array}{l}1320 \\
3292\end{array}$ & 300.7 & 47.9 & 0.01012 & $\begin{array}{l}0.160 \\
0.072\end{array}$ \\
\hline $\mathrm{L}_{2-1}$ & 25 & $18: 44: 10$ & $40-41.5$ & 1141 & $\begin{array}{l}3240 \\
3533\end{array}$ & 309.5 & 21.5 & 0.00156 & $\begin{array}{l}0.020 \\
0.081\end{array}$ \\
\hline $\mathrm{L}_{2-2 n}$ & 26 & $05: 24: 02$ & $42-44$ & 965 & $\begin{array}{l}3000 \\
3769\end{array}$ & 306.4 & 50.3 & 0.00343 & $\begin{array}{l}0.110 \\
0.129\end{array}$ \\
\hline $\mathrm{L}_{2-2 s}$ & 26 & 05:24:02 & $30-31.5$ & 0 & $\begin{array}{l}2040 \\
2721\end{array}$ & 310.1 & 23.5 & 0.00206 & $\begin{array}{l}0.022 \\
0.171\end{array}$ \\
\hline $\mathrm{L}_{2-3}$ & 26 & $17: 48: 33$ & $38.5-40$ & 0 & $\begin{array}{l}3960 \\
4519\end{array}$ & 303.3 & 33.1 & 0.00158 & $\begin{array}{l}0.013 \\
0.085\end{array}$ \\
\hline $\mathrm{L}_{2-4}$ & 27 & $04: 28: 25$ & $37.5-39$ & 0 & $\begin{array}{l}4200 \\
4519\end{array}$ & 304.9 & 31.5 & 0.00189 & $\begin{array}{l}0.019 \\
0.107\end{array}$ \\
\hline $\mathrm{L}_{2-5}$ & 28 & $17: 36: 20$ & $34.5-35$ & 0 & $\begin{array}{l}3360 \\
4666\end{array}$ & 302.2 & 56.8 & 0.00200 & $\begin{array}{l}0.052 \\
0.046\end{array}$ \\
\hline UTD1 & 22 & 18:13:06 & $39-40$ & 0 & $\begin{array}{l}8280-10800 \\
8601-9901\end{array}$ & 334.5 & 17.0 & 0.00126 & $\begin{array}{l}0.021 \\
0.014\end{array}$ \\
\hline UTD2 & 23 & $17: 17: 34$ & $36-37$ & 0 & $\begin{array}{l}7080-9120 \\
6001-8601\end{array}$ & 327.5 & 49.2 & 0.00116 & $\begin{array}{l}0.015 \\
0.018\end{array}$ \\
\hline UTD3 & 23 & 03:14:07 & $37.5-38$ & 0 & $\begin{array}{l}6720-11880 \\
6001-11201\end{array}$ & 324.0 & 19.1 & 0.00080 & $\begin{array}{l}0.004 \\
0.003\end{array}$ \\
\hline UTD4 & 24 & $16: 21: 57$ & $34-35$ & 0 & $\begin{array}{l}5520-7800 \\
5350-8601\end{array}$ & 325.6 & 27.3 & 0.00093 & $\begin{array}{l}0.004 \\
0.015\end{array}$ \\
\hline
\end{tabular}

* upper=CALIPSO observation; lower=RC4 dust model. For UTD, bottom-top height.

Beijing on 24 May (Fig. 2d). The time-height plot of dust extinction at Beijing shows a dense deep dust layer from the surface to 3-4 km from 24 May; this dust layer was so thick that the lidar signal was unable to penetrate into the free atmosphere. On 25 May, the cold front moves to the Sea of Japan and Shanghai (Fig. 2e), and the dust cloud accompa- nied by the cold front passes Seoul. The cold front and first dust cloud pass over Nagasaki and Toyama on 26 May. The RC4 model correctly reproduced both the correct timing of their arrival and the dust layer height. 


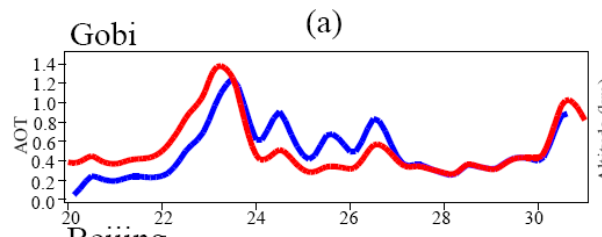

(b)
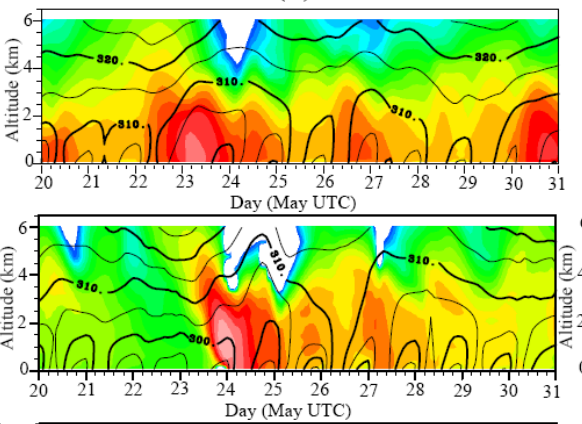

Day (May UTC)

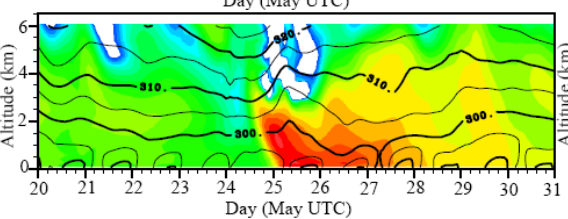

Day (May UTC)
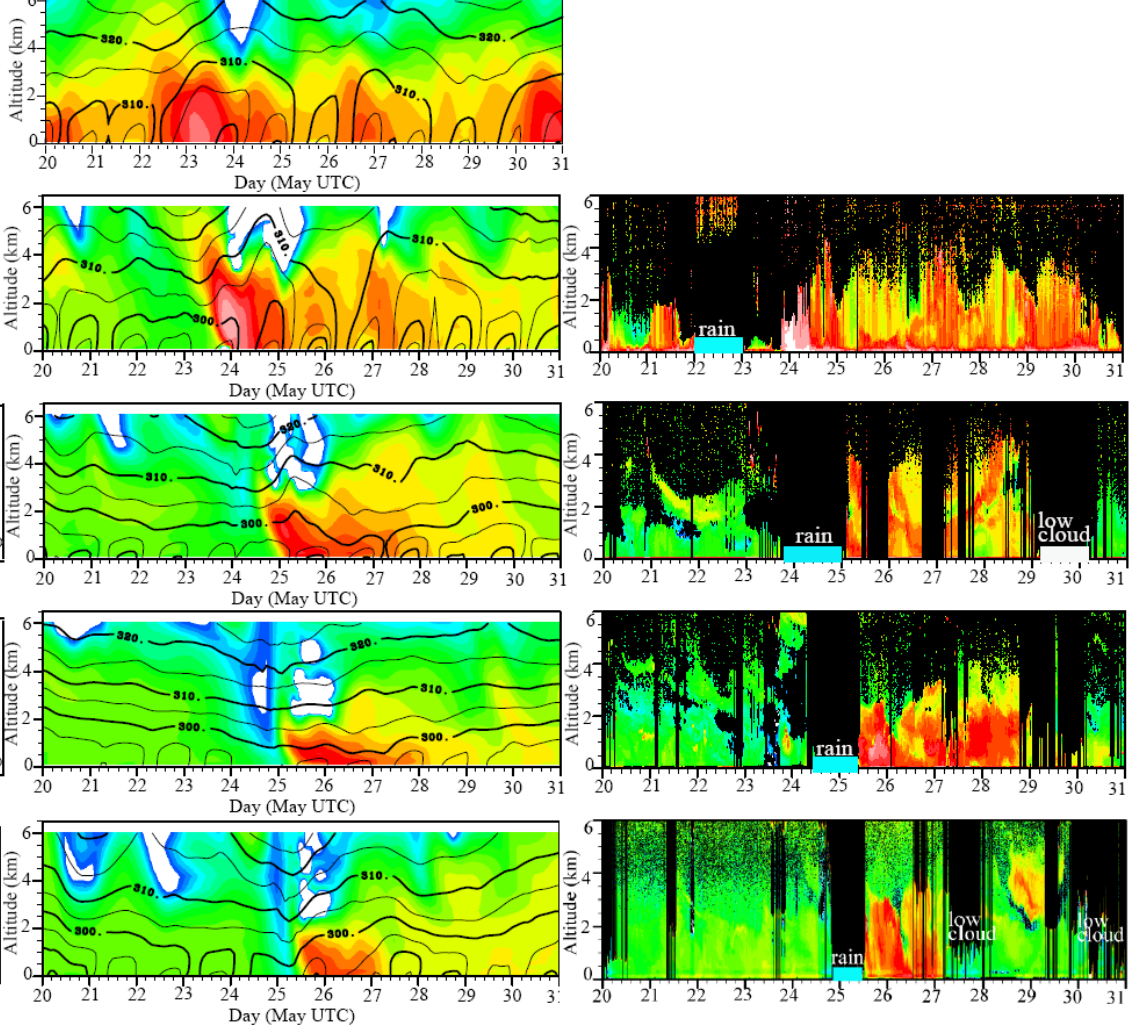

(c)
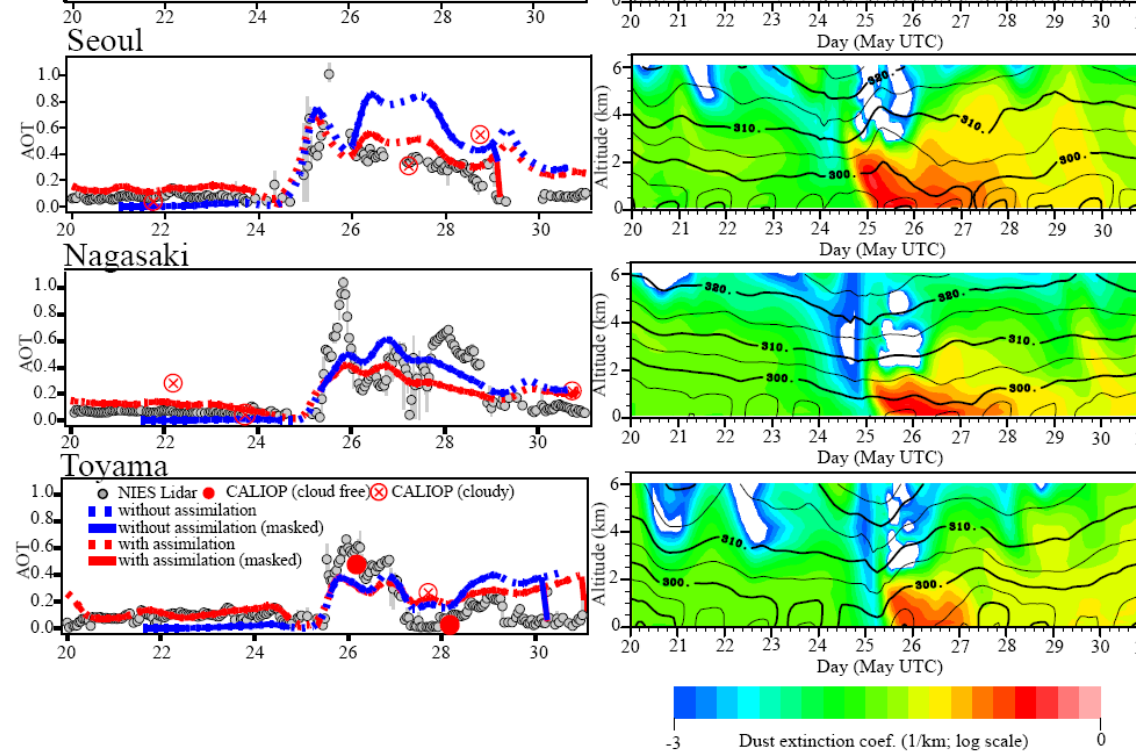

Dust extinction coef. (1/km; log scale $)$

Fig. 3. (a) Comparisons of NIES lidar (gray circles) and RC4 dust AOT (lines). AOT is calculated to a height of less than $6 \mathrm{~km}$ for the Gobi, Beijing, Seoul, Nagasaki, and Toyama locations. The blue line shows the result without assimilation; the red line shows that with assimilation. Symbols (solid and open-cross circle) are AOT derived from CALIOP, as described in the text. (b) The time-height cross section of the simulated dust extinction coefficient $\left(\mathrm{km}^{-1}\right)$ and potential temperature $(\mathrm{K})$. (c) Dust extinction coefficient observed by lidar $\left(\mathrm{km}^{-1}\right)$.

The subsequent $\mathrm{L}_{2}$ passes Beijing during 26-27 May. The TH plot at Beijing portrays an important meteorological condition in this period. The vertical gradient of potential temperature takes an isothermal profile from the surface to $5 \mathrm{~km}$ altitude on 12:00 UTC 26 May; then the dust layer depth increases both in observation and RC4 results. The MODIS cloud images (Fig. 2f) show that $\mathrm{L}_{2}$ locates in the northwest of Beijing on 26 May and that Beijing is the warm sector; the transported dust is also within this sector. In the warm sector of the low-pressure system, the ascending air motion plays an important role in upward transport of dust from PBL to the free atmosphere. In addition, $\mathrm{L}_{2}$ moves to Northeast China from East Mongolia on 27-28 May. At Seoul, the elevated dust layer is apparent on 27-28 May, reaching $4 \mathrm{~km}$ altitude. Then, $\mathrm{L}_{2}$ moves to North Korea on 29 May. An elevated dust layer is also detected at Toyama from 28 to 29 May in the vertical range of 3-5 km elevation. At Nagasaki, dust continues to appear only within the PBL, which indicates that the structure of the second dust cloud is split into two parts: the northern part of the Japan islands are mainly affected by the warm sector dust uplift and formation of the elevated dust layer, although the southern part of the Japan is controlled by the cold front. The dust layer remains mainly within the PBL. We will explain the observed and simulated warm sector dust uplift in Sect. 3.4.

The RC4 dust model assimilated with the NIES lidar data shows improved agreement with lidar data at most sites. Table 1 shows the root-mean square differences (RMSDs) for results achieved with and without data assimilation. The RMSD of dust AOT between the model and NIES lidar was improved by $31-67 \%$ after introduction of data assimilation. In particular, at Beijing and Seoul, assimilated results significantly reduce overestimation of the dust extinction coefficient during the second event. However, at Nagasaki, RMSD was not improved because of the underestimation of the first dust cloud. The reason is thought to be that the lidar at Beijing was unable to retrieve the first dust layer entirely because the dust layer was too thick for optical observations. These 
missing observation data are important for inverse correction of this underestimation.

Apparently, the variation of CALIOP AOT in Toyama was explained well by ground-based lidar and RC4. However, we found also that the variation of CALIOP AOT under clearsky conditions is less than that of either NIES lidar or RC4. This underestimate might result from differences of $S_{1}$ values between NIES lidar and the CALIOP inversion process. Available observation timing between CALIOP and NIES lidar remains limited. For that reason, we must accumulate more observations to produce sufficient quantitative verification.

3.3 Cross-section analysis along the cold front movement with CALIOP and RC4 model

This section presents tracking analyses of the vertical crosssection of dust following the movement of the $L_{1}$ cold front.

Figure 4 shows the vertical cross-section analysis of the particle depolarization ratio (PDR) at $532 \mathrm{~nm}$, dust extinction coefficient along CALIPSO paths, and averaged vertical profiles of the dust extinction coefficient for $L_{1}-2, L_{1}-4, L_{1}$ 6 , and $\mathrm{L}_{1}-8$ across the first dust storm. The CALIOP data were screened with conditions of $0.01<\mathrm{PDR}<1$, attenuated backscatter coefficient $>8 \times 10^{-4}\left(\mathrm{~km}^{-1}\right)$ to avoid observation noise and $\mathrm{CAD}<90$ to screen out dense clouds.

In the figure, $\mathrm{L}_{1}-2$ is crossing the center of $\mathrm{L}_{1}$. An aerosol layer with high PDR, thought to comprise mainly dust, is portrayed in Fig. 4a. Examination over the source region $\left(L_{1}-2\right)$ clarified that the model reproduced the dust mixing height correctly during the dust outbreak. According to Fig. 4b-d it shows a vertical cross section across the cold front and dry slot area, both modeled and observed cross sections have very similar structures both vertically and horizontally. Cloud bands created by the cold front can be observed along the region for which the modeled relative humidity is considerably high; dust aerosols are visible in the PBL behind the cloud band. Because the low-pressure system $L_{1}$ develops, the potential temperature drops gradually; it reaches a minimum value of $296.9 \mathrm{~K}$ on $\mathrm{L}_{1}-6$ at May 25 17:00 UTC. Based on this cold-front tracking analysis, we found that the first dust cloud behind a cold front maintains the PBL height of around $2-3 \mathrm{~km}$ from the continent to the Pacific Ocean within the latitudes of $30-44^{\circ} \mathrm{N}$; it then covers a wide region of Eastern Asia with high-level dust concentrations. Another interesting point is the change of PDR from the dust source region to the downwind region, i.e., PDR decreases gradually in direct relation to the transport distance, especially in a part of the surface layer. Detailed analyses will be described in Sect. 3.6.

\subsection{Analysis of warm sector dust uplift}

In this section, we specifically address the vertical structure of dust between $\mathrm{L}_{1}$ and $\mathrm{L}_{2}$. We also present cross-
Table 3. Starting locations of forward trajectories.

\begin{tabular}{llllll}
\hline Label & $\begin{array}{l}\text { Date } \\
\text { May }\end{array}$ & UTC & $\begin{array}{l}\text { Starting point of } \\
\text { forward trajectory }\end{array}$ & $\begin{array}{l}\text { Altitude from } \\
\text { sea level }(\mathrm{m})\end{array}$ & $\begin{array}{l}\text { Surface } \\
\text { elevation }(\mathrm{m})\end{array}$ \\
\hline $\mathrm{T}-1$ & 23 & $19: 00$ & $42.0^{\circ} \mathrm{N}, 108.3^{\circ} \mathrm{E}$ & 2022 & 1273 \\
$\mathrm{~T}-2$ & 25 & $19: 00$ & $42.0^{\circ} \mathrm{N}, 111.4^{\circ} \mathrm{E}$ & 4638 & 1430 \\
$\mathrm{~T}-3$ & 25 & $19: 00$ & $40.0^{\circ} \mathrm{N}, 110.8^{\circ} \mathrm{E}$ & 1460 & 1084 \\
\hline
\end{tabular}

section analyses of warm sector uplift and cold sector transport within PBL.

Figure 5 is the same as Fig. 4, but for the vertical structure $\mathrm{L}_{2}-1, \mathrm{~L}_{2}-2, \mathrm{~L}_{2}-4$, and $\mathrm{L}_{2}-5$ across the second low $\mathrm{L}_{2}$. Figures depicting $\mathrm{L}_{2}-2$ and $\mathrm{L}_{2}-4$ are unclear because these were taken during the CALIPSO daytime path with a small signal-to-noise ratio. Therefore, to outline the dust layer, we added a red broken line from the RC4 extinction coefficient value of $0.07\left(\mathrm{~km}^{-1}\right)$. Figure $5 \mathrm{~b}$ and $\mathrm{c}$ show that the potential temperature profile at northern latitudes is unstable. From a snapshot of the $\mathrm{L}_{2}-4$ path on 04:00 UTC 27 May (Fig. 5c), a marked dust structure is visible, with an elevated dust layer at northern latitudes $\left(38-48^{\circ} \mathrm{N}\right)$ between $2 \mathrm{~km}$ and $6 \mathrm{~km}$ altitude and a low-altitude dust layer in southern latitudes (30$\left.38^{\circ} \mathrm{N}\right)$.

Figure $5 \mathrm{c}$ is important for its presentation of clear evidence of the warm sector dust uplift from PBL to the free atmosphere near the source region. A MODIS image (Fig. 2g) shows the $\mathrm{L}_{2}-4$ path immediately across the warm sector of low-pressure system $\mathrm{L}_{2}$, which suggests that the driving force producing the elevated dust layer is a dynamic warm-sector updraft associated with low-pressure system activity. Trajectory analysis of the elevated dust layer using the Hybrid Particle Transport Model (HYPACT) (Walko et al., 2001) based on RAMS output shows that the updraft dominates from the surface to the middle troposphere near Beijing on 26 May. Then the dust cloud is elevated to about $4 \mathrm{~km}$ height with a typical ascending speed of $2 \mathrm{~km} / 12 \mathrm{~h}$. This trajectory analysis will be described in Sect. 3.5.

The vertical structures retrieved by CALIOP presented in Fig. 5 are consistent with those by NIES lidar measurements in Sect. 3.2. As portrayed in Figs. 2 and 5, the dust layer is beneath a thick cloud. However, RC4 results reveal that the boundary dust layer of thickness of $2 \mathrm{~km}$ passed over the East China Sea at latitudes of $30-36^{\circ} \mathrm{N}$, as depicted in Fig. 5c and d.

\subsection{3-D structure of dust cloud transport by low-pressure system}

We conduct Lagrangian forward trajectory analysis using HYPACT to investigate different transport structures of dust accompanying $\mathrm{L}_{1}$ and $\mathrm{L}_{2}$. Table 3 shows HYPACT trajectory information. 

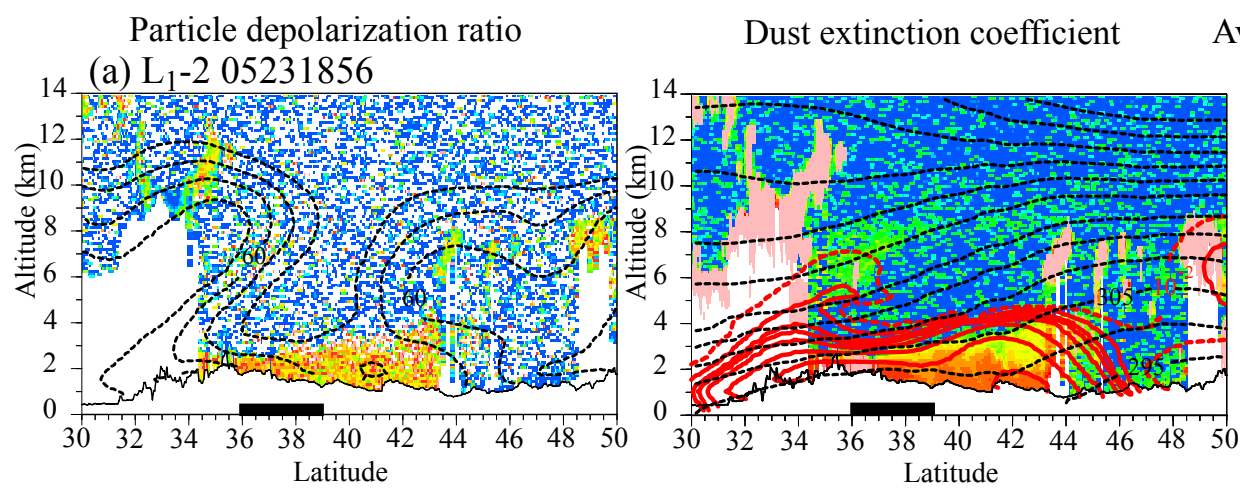

Averaged vertical profile
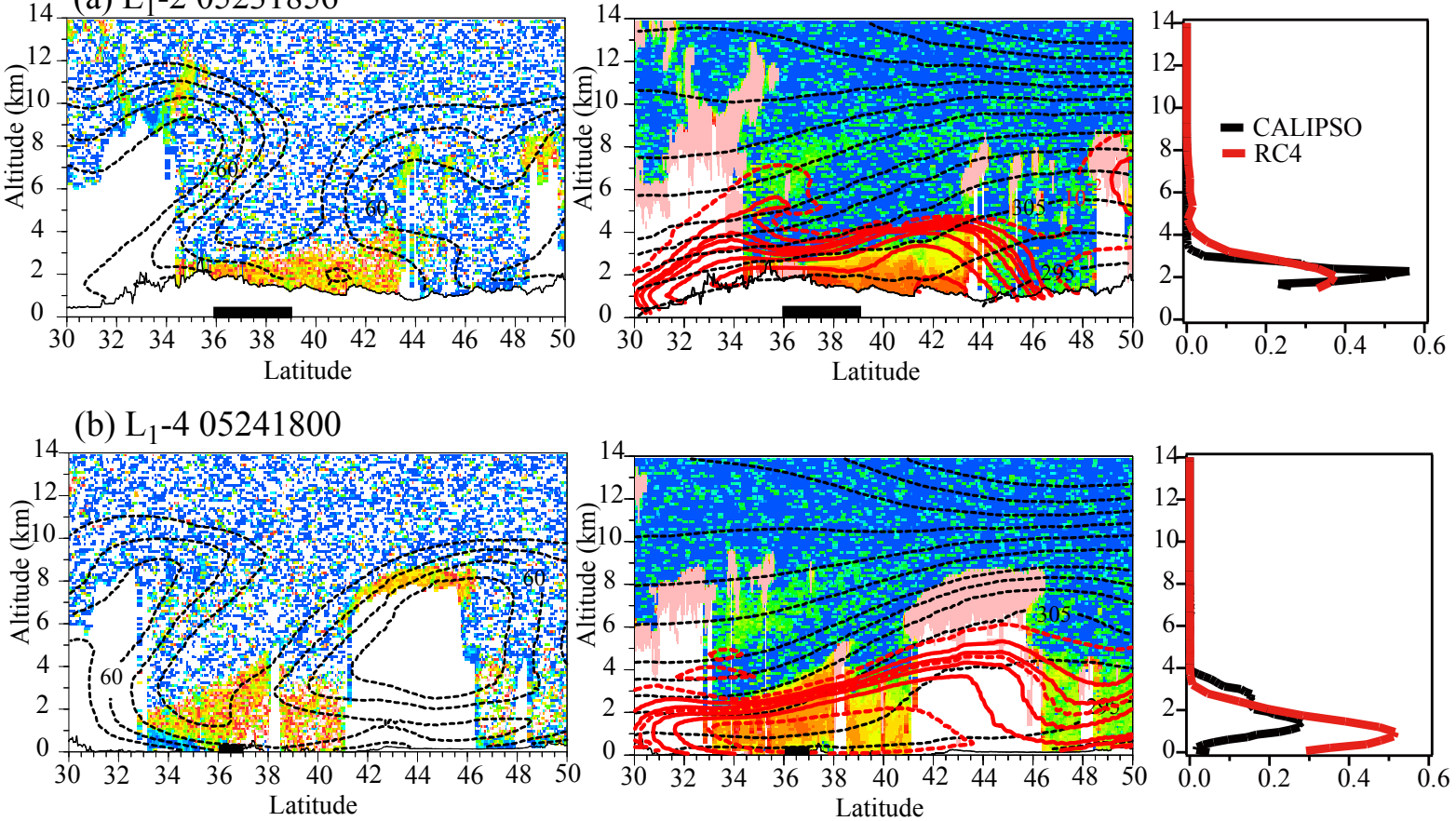

(c) $\mathrm{L}_{1}-605251705$
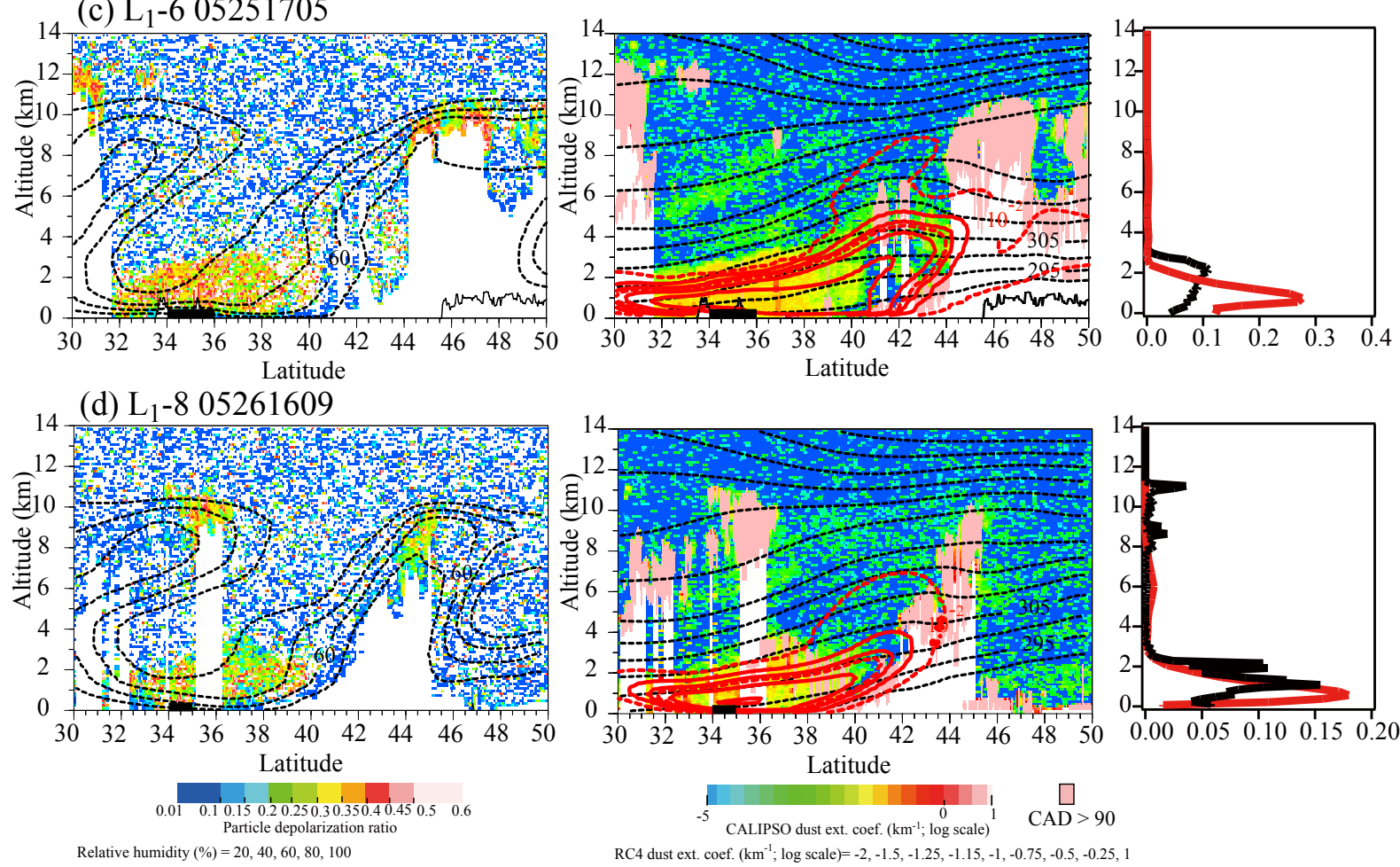

Potential temp. $(\mathrm{K})=290,295,300,305,310,315,320,330,340,350,360,370,380$

Fig. 4. (Left) Vertical cross-section of the CALIOP particle depolarization ratio and RAMS relative humidity (black dashed contour), (Middle) CALIOP dust extinction coefficient (color), RC4 dust extinction coefficient (thick red contour), RAMS potential temperature (black dashed contour) and region of $C A D>90$ (by light pink area) for paths $\mathrm{L}_{1}-2, \mathrm{~L}_{1}-4, \mathrm{~L}_{1}-6$, and $\mathrm{L}_{1}-8$. (Right) Averaged vertical profile of dust extinction coefficient for CALIOP and RC4 for $\mathrm{L}_{1}-2, \mathrm{~L}_{1}-4, \mathrm{~L}_{1}-6$, and $\mathrm{L}_{1}-8$. 

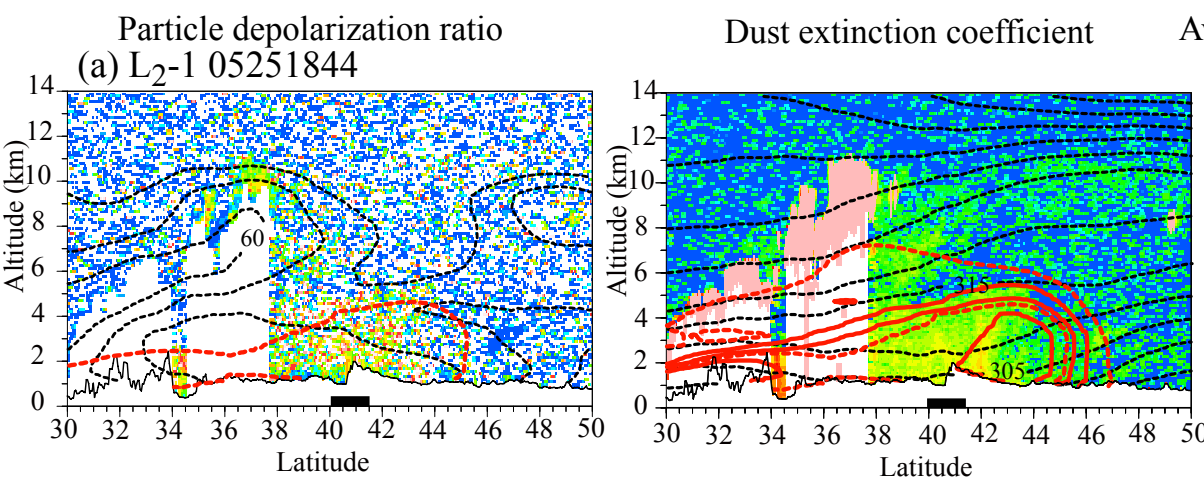

Averaged vertical profile

(b) $\mathrm{L}_{2}-205260524$
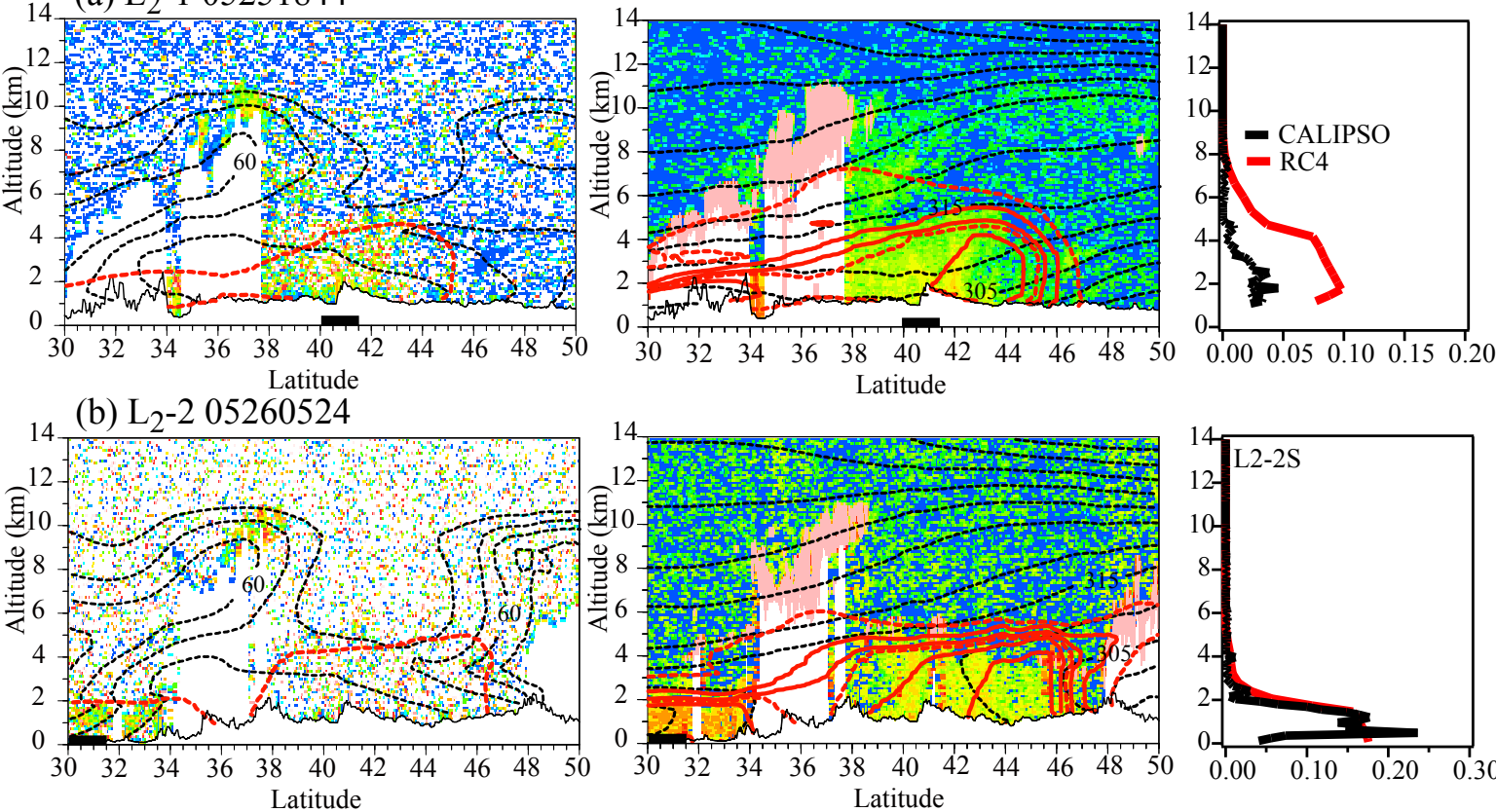

(c) $\mathrm{L}_{2}-405270428$
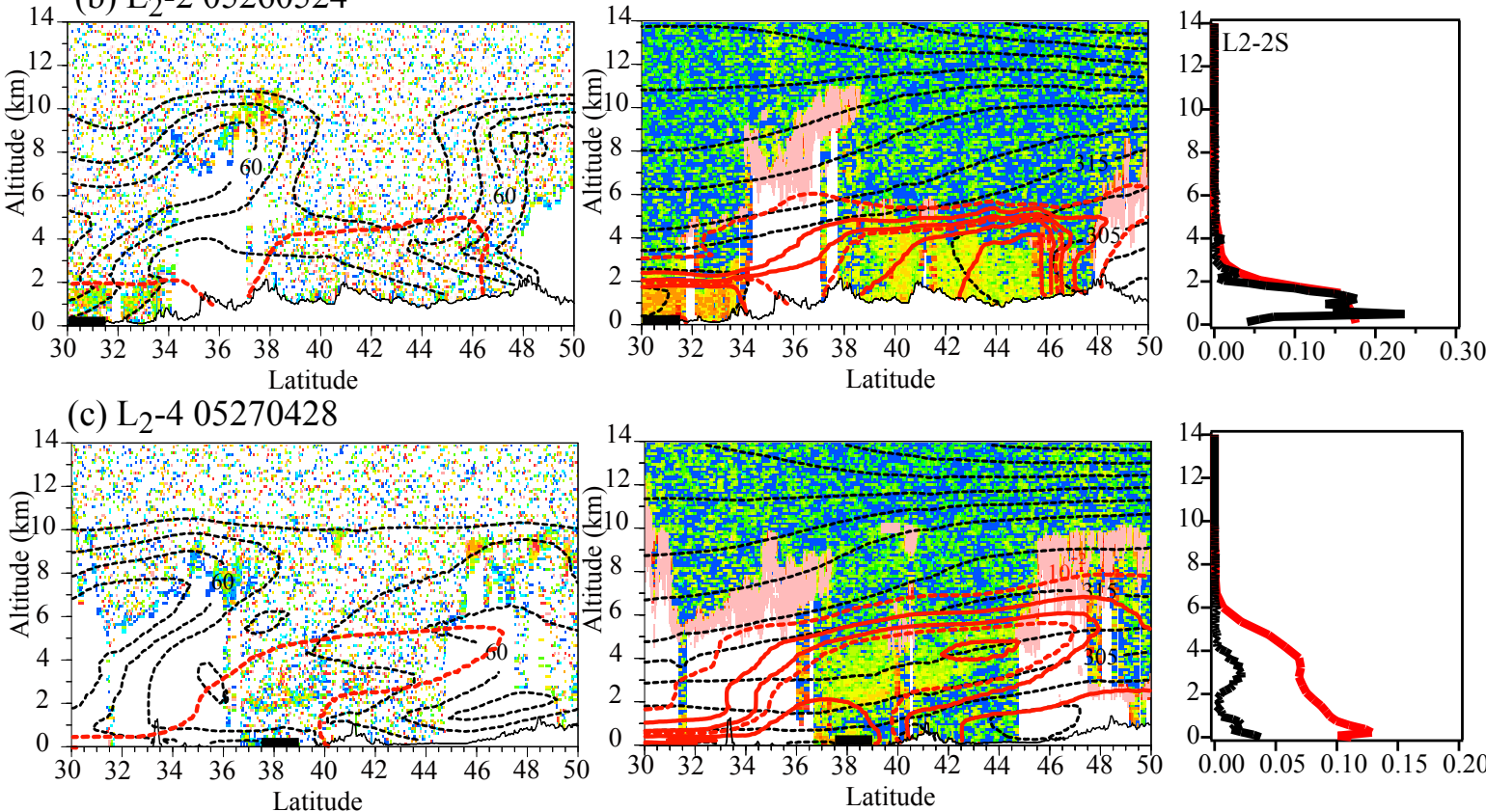

(d) $\mathrm{L}_{2}-505281736$
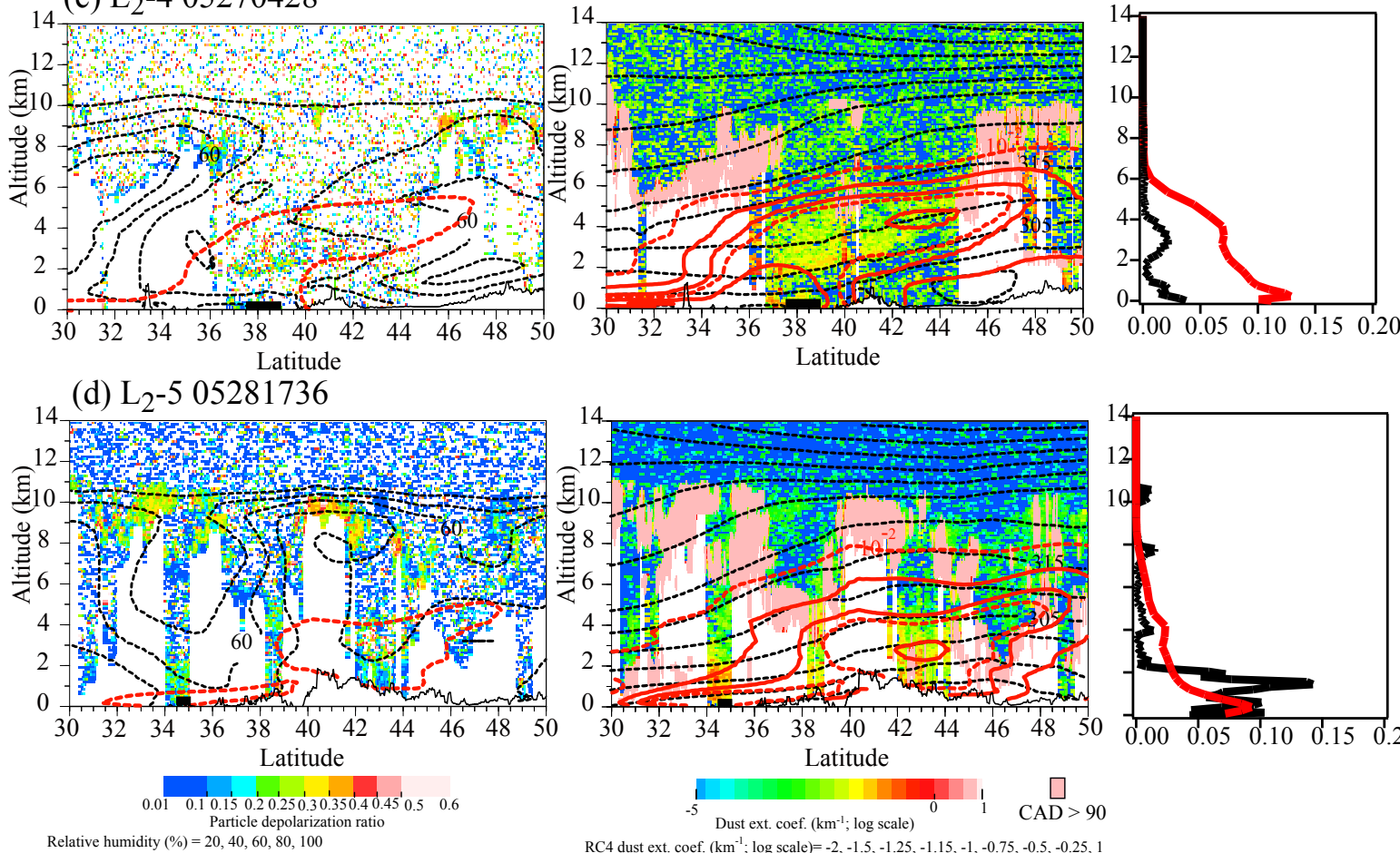

Potential temp. $(\mathrm{K})=290,295,300,305,310,315,320,330,340,350,360,370,380$

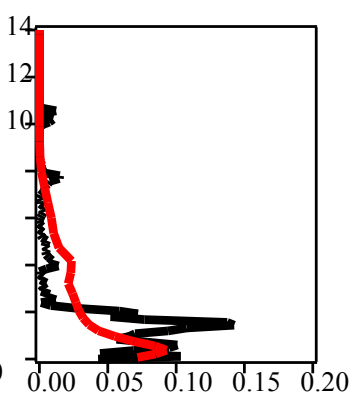

Fig. 5. Same as Fig. 4, but for $L_{2}-1, L_{2}-2, L_{2}-4$, and $L_{2}-5$.

The 3-D transport structure of the first dust cloud, which occurred on 23 May from the Gobi region, is presented in Fig. 6 with T-1 forward trajectory analysis. Figure $6 a-d$ show dust extinction coefficients along CALIPSO paths for $\mathrm{L}_{1}-2, \mathrm{~L}_{1}-4, \mathrm{~L}_{1}-6$, and $\mathrm{L}_{1}-8$. The vertical cross section of the dust extinction coefficient and potential temperature from
RC4 along the T-1 trajectory are depicted in Fig. 6e. The masked area in Fig. 6e is an updraft region simulated by the RC4 dust model. Figure $6 f$ shows the dust AOT and surface wind speed interpolated temporally and spatially along the CALIPSO path time. 

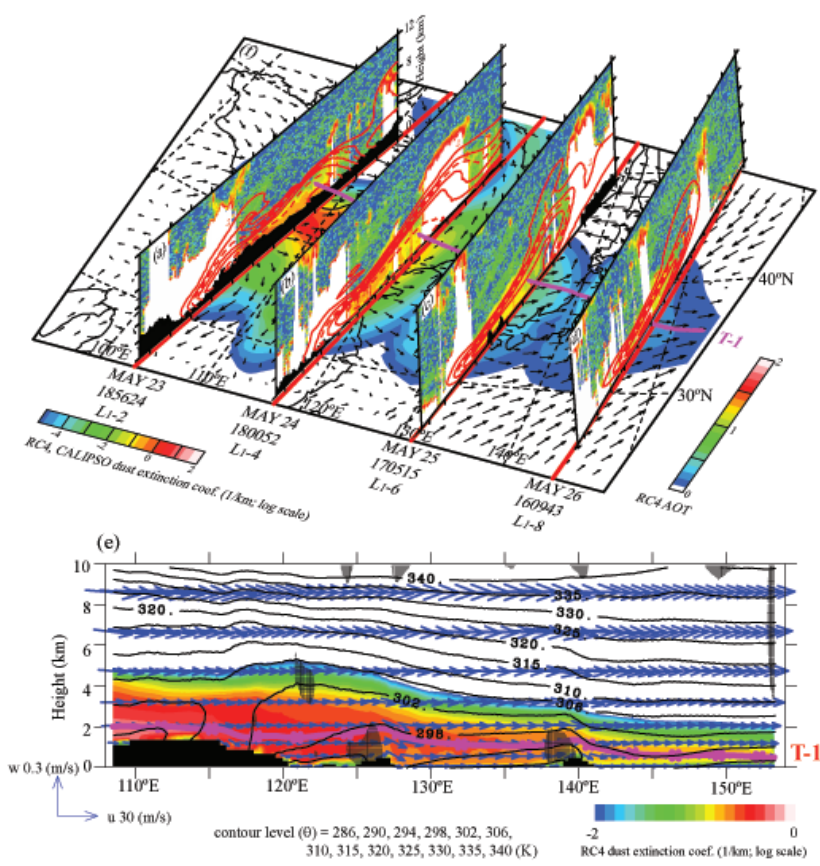

Fig. 6. 3-D analysis of a CALIOP and RC4 cross-section. (a)(d) Vertical cross-sections of the CALIPSO path $\left(\mathrm{L}_{1}-2, \mathrm{~L}_{1}-4, \mathrm{~L}_{1}-6\right.$, and $\mathrm{L}_{1}-8$ ) by CALIOP dust extinction (color) and RC4 dust extinction coefficient (thick red line). Red lines (T-1) show forward trajectories starting from north of $\mathrm{L}_{1}-2$ (start May 23 19:00 UTC at $2022 \mathrm{~mm}$ m.s.1.). (e) The longitudinal cross-section along the T-1 from the RC4 dust extinction coefficient (color), potential temperature (contour), and $\mathrm{u}-\mathrm{w}$ wind vector.

The T-1 trajectory corresponds with CALIOP observation in the time and trajectory location. The T-1 trajectory maintains altitude of $1 \mathrm{~km}$; it travels nearly $1500 \mathrm{~km} \mathrm{day}^{-1}$. The 3-D transport structure, in which dust is trapped within the potential temperature between 295 and $305 \mathrm{~K}$, is readily apparent; the dust travels within PBL for a long distance. The horizontal advection and the descending air motion behind the cold front depress the vertical diffusion of dust. Figure $6 \mathrm{f}$ shows that the dust AOT outbreak follows the westerly wind: a clear change in wind direction is visible at the center of the low-pressure system. Figure 6 presents the very typical 3-D structure of dust transport accompanied by the cold front and low-pressure system.

Figure 7 is identical to Fig. 6 except for the second dust cloud associated with low-pressure system $\mathrm{L}_{2}$. Therein, $\mathrm{T}$ 2 shows the trajectory analysis of a dust cloud taken in the cold sector; T-3 shows analysis of the elevated dust cloud. Figure $7 \mathrm{e}$ presents the vertical cross section along trajectory T-3.

The T-2 trajectory time of passage coincides with the CALIOP cross-section measurement, although the T-3 trajectory does not completely match up with the CALIOP cross section because of slower transportation of T-3 trajectory. Therefore, the elevated dust layer is not clearly visible
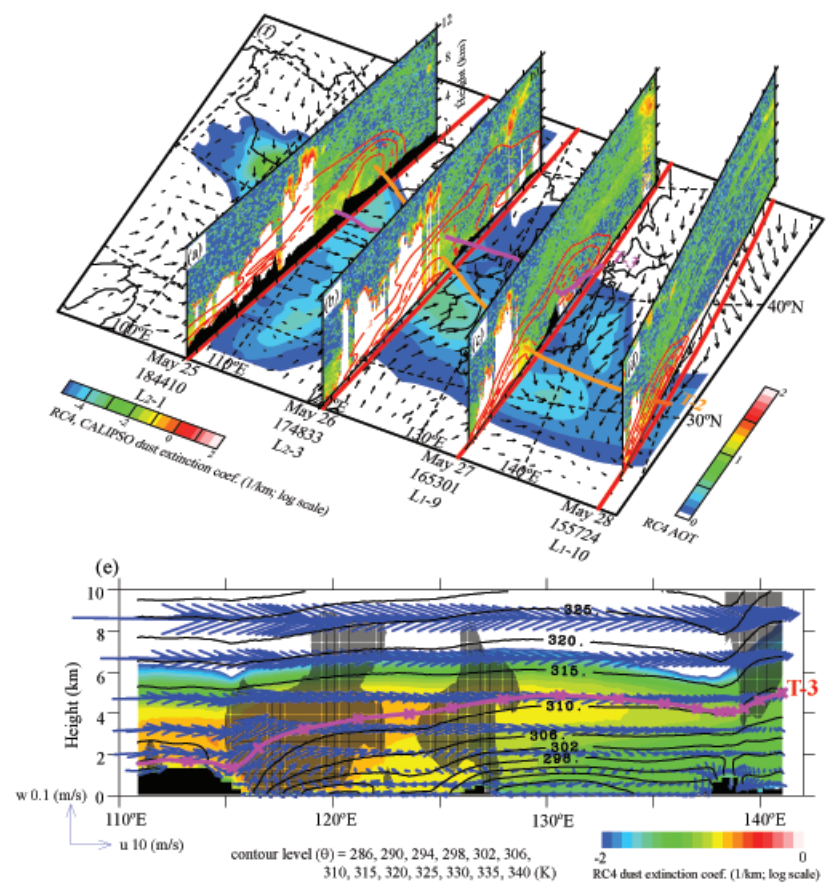

Fig. 7. 3-D analysis of CALIOP and RC4 cross-section. (a)-(d) Vertical cross-sections of the CALIPSO path $\left(\mathrm{L}_{2}-1, \mathrm{~L}_{2}-3, \mathrm{~L}_{1}-9\right.$, and $\mathrm{L}_{1}-10$ ) by CALIOP dust extinction (color) and RC4 dust extinction coefficient (thick red line). The orange line (T-2) and red line (T-3) respectively depict forward trajectories from the $\mathrm{L}_{2}-1$ path starting at May 25 19:00 UTC at $4638 \mathrm{~m}$ and $1460 \mathrm{~mm}$.s.l. (e) Longitudinal cross-section along the T-3 from RC4 dust extinction coefficient (color) and the potential temperature (contour) and $\mathrm{u}-\mathrm{W}$ wind vector.

in Fig. 7c and d. Nevertheless, this figure clearly depicts two significant transport structures associated with cold and warm air advection around the low-pressure system $\mathrm{L}_{2}$. The $\mathrm{T}-2$ trajectory was departing from a northern point; it traveled southward at a horizontal speed of $1500 \mathrm{~km} \mathrm{day}^{-1}$, maintaining $2 \mathrm{~km}$ altitude. The T-3 trajectory was departing within a warm sector; it ascended from the ground to $4 \mathrm{~km}$ at about $116^{\circ}$ E. Subsequently, the T-3 trajectory traveled on colder stable layer slowly with speed of $900 \mathrm{~km} \mathrm{day}^{-1}$; it reached Toyama on 00:00 UTC 29 May (see Fig. 3c at Toyama). As depicted in Fig. 7e, the dynamical updraft in the warm sector of the low-pressure system is an important meteorological mechanism producing an elevated dust layer that plays an important role in long-range transport. The formation of the elevated dust layer tends to occur under a meteorological situation of sequential outbreaks of two low-pressure systems; a typical example is apparent in the so-called ACE-Asia "Perfect Dust Storm" (Uno et al., 2004). This mechanism is important for supplying nutrition, through long-range transport, to the distant open ocean.

Transport within the cold sector is also an important process because human society is strongly affected by 

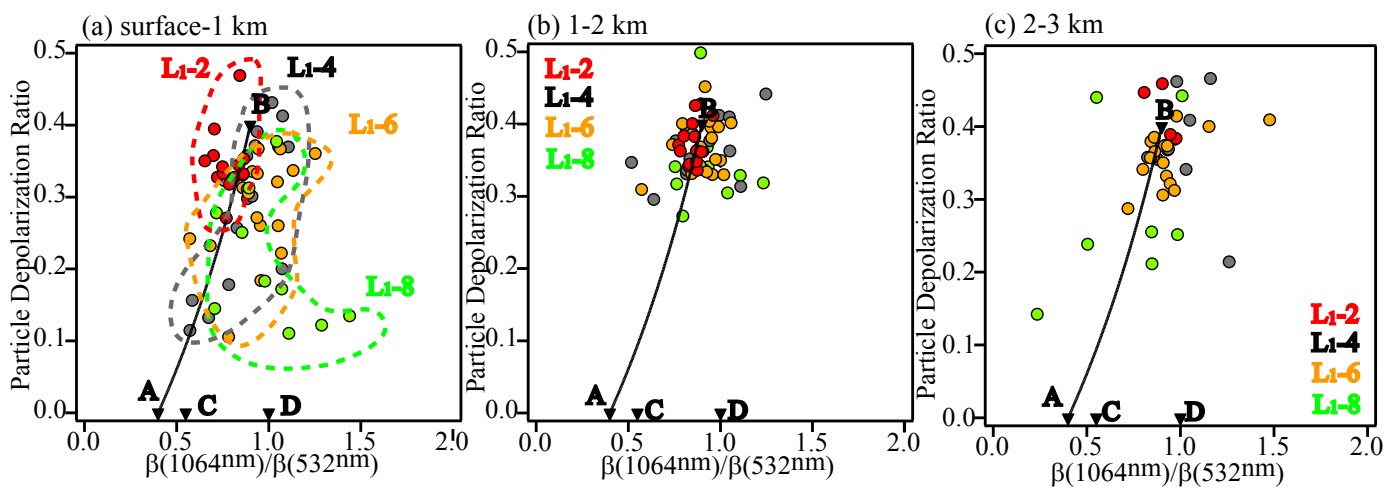

Fig. 8. Scatter diagram of the particle depolarization ratio (PRD) and the color ratio (CR) derived from $\mathrm{L}_{1}-2, \mathrm{~L}_{1}-4, \mathrm{~L}_{1}-6$, and $\mathrm{L}_{1}-8 \mathrm{CALIOP}$ data for three altitude levels. The solid line represents the theoretical curve for an external mixture of sulfate (A) and dust (B).

dust-polluted PBL and dust cloud passage through the industrial areas of Eastern Asia. Therefore, complicated processes of internal and external mixing occur between dust and anthropogenic aerosols, in which the mixing status plays an important role in human health and radiative balance. In the next section, we examine the change of optical properties of dust clouds during outflow using the wavelength ratio and aerosol depolarization ratio retrieved by CALIOP.

An $L_{1}$ event is characterized as a severe dust storm with the low average potential temperature of $301.7 \mathrm{~K}$. An $\mathrm{L}_{2}$ dust event is understood to be a more moderate dust event than $\mathrm{L}_{1}$, with average potential temperature of $305.5 \mathrm{~K}$ at each altitude of the dust layer. The maximum dust extinction coefficient derived from CALIOP is $0.349 \mathrm{~km}^{-1}$ on the $\mathrm{L}_{1}-2$ path. The dust layer depth (see Table 2) behind the cold front of $L_{1}$ is $1320-3120 \mathrm{~m}$ (1847-4149 m) from CALIOP (from RC4). For the $\mathrm{L}_{2}$ event, the dust depth is $2040-4200 \mathrm{~m}$ (2721-4666 m) for observation (RC4). Actually, RC4 tends to overestimate the dust layer depth because of coarser vertical resolution than CALIOP measurement. However, a good correlation coefficient of 0.743 is obtained between the simulated and observed layer depth. The UTD (Table 2) layer is also apparent on 22-24 May; the dust layer heights are 5520 $11880 \mathrm{~km}(5350-11201 \mathrm{~km})$ based on CALIOP (RC4); the dust layer peaks are higher than $6 \mathrm{~km}$. The origin of this UTD can be considered as regions other than the Gobi region because of the considerably high altitude of the dust layer (e.g. Taklimakan Desert region; Liu et al., 2008).

Generally, the dust layer height is modulated by the potential temperature level of the dust layer and stratification in the downstream region. As described in this section, the lowpressure system also plays an important role in redistribution of dust layer (see Figs. 6e and 7e).

3.6 Correlation of the color ratio and particle depolarization ratio

The CALIOP device provides aerosol information for the two wavelengths of 532 and $1064 \mathrm{~nm}$. The wavelength ratio of aerosol backscattering coefficients (defined as the color ratio: CR) provides the aerosol size information. The relationship between CR and the particle depolarization ratio (PRD) plays an important role in aerosol characterization (Sugimoto et al., 2002). Therefore, the scatter diagram derived from CALIOP is useful to clarify aging of pure dust particles during long-range dust transport. We analyzed CALIOP data between $30^{\circ} \mathrm{N}$ and $44^{\circ} \mathrm{N}$ based on T-1 trajectory analysis and Fig. 4 to investigate the same dust mass. We applied the screening method described in Sect. 3.3 to exclude the cloud layer.

Figure 8 portrays a scatter diagram of $\mathrm{CR}$ and $\mathrm{PDR}$ from $\mathrm{L}_{1}-2, \mathrm{~L}_{1}-4, \mathrm{~L}_{1}-6$, and $\mathrm{L}_{1}-8$ data for three altitude levels between $30^{\circ} \mathrm{N}$ and $44^{\circ} \mathrm{N}$. The CALIOP data were averaged within $39.3 \mathrm{~km}$ horizontally and $1 \mathrm{~km}$ vertically. The solid triangles respectively show arbitrary values for the pure sulfate (A), pure dust (B), sea salt accumulation mode (C) and sea salt coarse mode (D). The solid line shows the theoretical curve for an external mixture of $\mathrm{A}$ and $\mathrm{B}$.

A clear difference of aerosol characteristics is apparent among paths, particularly in Fig. 8a: in the $\mathrm{L}_{1}-2$ dust source region, aerosol particles uniformly have high PDR greater than 0.3 , with $C R$ of $0.7-0.86$. The $\mathrm{L}_{1}-2$ data are considered to show information of pure dust particles that have just been emitted from the Gobi region. The dust cloud is transported down to the east; then PDR decreases gradually. However, the $\mathrm{CR}$ does not change much. Across Northeast China, the $\mathrm{L}_{1}-4$ data points fall on a theoretical curve of the external mixture of sulfate and dust; the $\mathrm{L}_{1}-6$ data points across Japan fall under the theoretical curve. Finally, regarding $\mathrm{L}_{1}-8$ data over the Pacific Ocean, some dots are distributed in high CR and low PDR. In addition to the mixing of dust and sulfate, the possibility exists that dust particles were mixed with sea salt because data were obtained for PBL over the ocean.

Several processes alter and age dust particles. Sizedependent gravitational settling and dry/wet deposition of dust particles and internal or external mixing of dust and air pollutant particles are main processes of decreasing PDR. 
In Eastern Asia, emissions of anthropogenic pollutants have increased concomitantly with recent rapid Asian economic growth. Therefore, it is usually difficult to separate effects of pollutants from those of dust deposition processes for decreasing PDR. Application of a regional chemical transport model, CMAQ (Byun et al., 1999; Uno et al., 2007), shows that high concentrations of anthropogenic pollutants such as $\mathrm{O}_{3}$ and sulfate aerosols were also transported within the dry slot behind the cold front line of $\mathrm{L}_{1}$. The CMAQ results support the strong possibility of mixing of dust and sulfate during low-altitude dust transport. Additionally, RC4 predicted high concentration fields of sea salt in the boundary layer over $\mathrm{L}_{1}-8$. Therefore, aerosols in the layer were suggested to be a mixture of dust, sulfate, and sea salt. Figure $8 \mathrm{a}$ can be understood as reflecting a typical aging process of pure dust with air pollutants and sea salt. In the upper altitude cases (b) and (c), such a clear aging step is not apparent, which suggests that the mixing of air pollutants occurred mainly at low altitude. As presented in Fig. 8a, both high and low PDR values were distributed at less than $1 \mathrm{~km}$ in latitudes of $32^{\circ}-38^{\circ} \mathrm{N}$, which suggests that, in low-altitude dust transport cases, mixing of dust and pollutants occurs frequently. This scatter diagram using data obtained by tracking the same dust cloud enables analyses of the aging of pure dust particles.

\section{Conclusions}

Detailed analyses incorporating the NASA space-borne lidar CALIOP, RC4 dust transport model, and the ground-based NIES lidar network clarified 3-D structures of Asian dust transport triggered by two subsequent low-pressure systems $\mathrm{L}_{1}$ and $\mathrm{L}_{2}$ during the end of May 2007. The NIES lidar observation data were used for dust model assimilation. Assimilated results mitigated overestimation of dust concentration by reducing $17.4 \%$ of dust emissions and improved the RMSD of dust AOT between the model and NIES lidar data by $31-67 \%$. Assimilated dust profiles by RC4 were verified using the CALIOP dust cross-section from the dust source region to the long-range downwind region down to the Pacific Ocean. Comparison revealed that the vertical and horizontal structure of dust clouds shown in RC4 results and CALIOP measurements coincided well.

We clarified two important transport mechanisms of Asian dust in the PBL and the free atmosphere: a low-altitude dust outbreak within the dry slot region of the well-developed low-pressure system, and formation of an elevated dust layer within the warm sector of the low-pressure system. The warm-sector uplifted dust layer was presented clearly by CALIOP and RC4. Results showed that the dust cloud located in the cold (warm) sector is transported within the boundary layer (up to the free atmosphere) through the lowpressure system, which has a descending (ascending) motion.
The aging of pure dust particles was investigated using the particle depolarization ratio (PDR) at $532 \mathrm{~nm}$ and the color ratio (CR) at $1064 \mathrm{~nm}$ and $532 \mathrm{~nm}$ for the low-altitude dust transport case by tracking nearly the same dust air mass. A clear difference of aerosol characteristics among paths was found in the layer of less than $1 \mathrm{~km}$ altitude: aerosols with uniformly high PDR were observed over the dust source region, whereas mixing states between air pollution aerosol and dust were found in the downwind region over Japan and the Pacific Ocean.

Results presented in this paper demonstrate that the integrated analysis of 3-D dust observation and numerical dust transport model plays an important role in elucidating and characterizing dust phenomena. For this study, we used different $S_{1}$ values for CALIOP and NIES lidar inversion. It is important to revisit and reanalyze the same dust event using the official CALIOP extinction coefficient based on the variable $S_{1}$ setting from NASA, which was released in 2008.

Acknowledgements. This work was partly supported by the Global Environment Research Fund of the Ministry of the Environment, Japan (C-061), and a Grant-in-Aid for Scientific Research under grant 17360259 from the Ministry of Education, Culture, Sports, Science and Technology, Japan. Lidar observations at Beijing were conducted with the cooperation of Z. Wang of the Institute of Atmospheric Physics, China, and NIES. The CALIPSO data were obtained from the NASA Langley Research Center Atmospheric Sciences Data Center. The MODIS cloud image used in Fig. 2 was obtained from the NRL/Monterey Aerosol Page (URL: http://www.nrlmry.navy.mil/aerosol).

Edited by: T. Garrett

\section{References}

Byun, D. W. and Ching, J. K. S.: Science algorithms of the EPA Models-3 community multi-scale air quality (CMAQ) modeling system, NERL, Research Triangle Park, NC EPA/ 600/R-99/030, 1999.

Fernald, F. G.: Analysis of atmospheric LIDAR observations: Some comments, Appl. Optics, 23, 652-653, 1984.

Liu, Z., Sugimoto, N., and Murayama, T.: Extinction-to-backscatter ratio of Asian dust observed with high-spectral-resolution LIDAR and Raman LIDAR, Appl. Optics, 41, 2760-2767, 2002.

Liu, Z., Vaughan, M. A., Winker, D. M., Hostetler, C. A., Poole, L. R., Hlavka, D., Hart, W., and McGill, M.: Use of probability distribution functions for discriminating between cloud and aerosol in lidar backscatter data, J. Geophys. Res., 109, D15202, doi:10.1029/2004JD004732, 2004.

Liu, Z., Liu, D., Huang, J., Vaughan, M., Uno, I., Sugimoto, N., Kittaka, C., Trepte, C., Wang, Z., Hostetler, C., and Winker, D.: Airborne dust distributions over the Tibetan Plateau and surrounding areas derived from the first year of CALIPSO lidar observations, Atmos. Chem. Phys., 8, 5045-5060, 2008, http://www.atmos-chem-phys.net/8/5045/2008/.

Shimizu, A., Sugimoto, N., Matsui, I., Arao, K., Uno, I., Murayama, T., Kagawa, N., Aoki, K., Uchiyama, A., and Yamazaki, 
A.: Continuous observations of Asian dust and other aerosols by polarization lidars in China and Japan during ACE-Asia, J. Geophys. Res., 109, D19S17, doi:10.1029/2002JD003253, 2004.

Sugimoto, N., Matsui, I., and Shimizu, A.: Observation of dust and anthropogenic aerosol plumes in the Northwest Pacific with a two-wavelength polarization lidar on board the research vessel Mirai, Geophys. Res. Lett., 29(19), 1901, doi:10.1029/2002GL015112, 2002.

Sugimoto, N., Shimizu, A., Matsui, I., Dong, X., Zhou, J., Bai, X., Zhou, J., Lee, C.-H., Yoon, S.-C., Okamoto, H., and Uno, I.: Network observations of Asian dust and air pollution aerosols using two-wavelength polarization Lidars, 23rd International Laser Radar Conference, July 2006 Nara, Japan, 23ILRC, ISBN 49902916-0-3, 851-854, 2006.

Takemura, T. and Uno, I.: Modeling study of long-range transport of Asian dust and anthropogenic aerosols from East Asia, Geophys. Res. Lett., 29(24), 2158, doi:10.1029/2002GL016251, 2002.

Uno, I., Amano, H., Emori, S., Kinoshita, K., Matsui, I., and Sugimoto, N.: Trans-Pacific yellow sand transport observed in April 1998: A numerical simulation, J. Geophys. Res., 106(D16), 18331-18344, 2001.

Uno, I., Satake, S., Carmichael, G. R., Tang, Y., Wang, Z., Takemura, T., Sugimoto, N., Shimizu, A., Murayama, T., Cahill, T. A., Cliff, S., Uematsu, M., Ohta, S., Quinn, P. K., and Bates, T. S.: Numerical study of Asian dust transport during the springtime of 2001 simulated with the Chemical Weather Forecasting System (CFORS) model, J. Geophys. Res., 109, D19S24, doi:10.1029/2003JD004222, 2004.

Uno, I., Wang, Z., Chiba, M., Chun, Y.-S., Gong, S., Hara, Y., Jung, E., Lee, S.-S., Liu, M., Mikami, M., Music, S., Nickovic, S., Satake, S., Shao, Y., Song, Z., Sugimoto, N., Tanaka, T., and Westphal, D.: Dust model intercomparison (DMIP) study over Asia - Overview, J. Geophys. Res., 111, D12213, doi:10.1029/2005JD006575, 2006.
Uno, I., He, Y., Ohara, T., Yamaji, K., Kurokawa, J.-I., Katayama, M., Wang, Z., Noguchi, K., Hayashida, S., Richter, A., and Burrows, J. P.: Systematic analysis of interannual and seasonal variations of model-simulated tropospheric $\mathrm{NO}_{2}$ in Asia and comparison with GOME-satellite data, Atmos. Chem. Phys., 7, 16711681, 2007, http://www.atmos-chem-phys.net/7/1671/2007/.

Uno, I., Yumimoto, K., Shimizu, A., Hara, Y., Sugimoto, N., Wang, Z., Liu, Z., and Winker, D. M.: 3D Structure of Asian Dust Transport revealed by CALIPSO Lidar and a 4DVAR Dust Model, Geophys. Res. Lett., 35, L06803, doi:10.1029/2007GL032329, 2008.

Yumimoto, K., Uno, I., Sugimoto, N., Shimizu, A., and Satake, S.: Adjoint inversion modelling of dust emission and transport over East Asia, Geophys. Res. Lett., 34, L08806, doi:10.1029/2006GL028551, 2007.

Yumimoto, K., Uno, I., Sugimoto, N., Shimizu, A., Liu, Z., and Winker, D. M.: Adjoint inversion modeling of Asian dust emission using lidar observations, Atmos. Chem. Phys., 8, 28692884, 2008, http://www.atmos-chem-phys.net/8/2869/2008/.

Walko, R. L., Tremback, C. J., and Bell, M. J.: HYPACT: Hybrid Particle And Concentration Transport Model User's Guide, ASTER Division, Mission Research Corp., 2001.

Winker, D. M., Hunt, W. H., and McGill, M. J.: Initial performance assessment of CALIOP, Geophys. Res. Lett., 34, L19803, doi:10.1029/2007GL030135, 2007. 